\title{
Enhancement of Forced Convection Heat Transfer for SiO2 flow through Channel with Ribs at Constant Heat Flux
}

\author{
Khudheyer, Ahmed F. and Nawaf, Taha S. \\ ${ }^{1}$ Khudheyer, Ahmed F. Al-nahrain University. IRAQ \\ ${ }^{2}$ Nawaf, Taha S. BSc Mechanical Engineering/ Al-nahrain University. IRAQ
}

\begin{abstract}
Numerical investigation of forced convective flow in a 2-dimensional microchannel. This investigation is analyzed with nanoparticles $\mathrm{SiO}_{2}$ and water as a base fluid studying the influence of turbulence model inside multi geometrical channel (Triangular, Trapezoidal, Semi-circular, and Rectangular) by using "Finite Volume Method (FVM)". The heat flux is applied on the lower wall of channel and the upper is insulated. The diameter of nanoparticles is $20 \mathrm{~nm}$. The Reynolds number ranges are from 10000 to 30000 for ratio of groove width $(\mathrm{B})$ to channel height $(\mathrm{H})$ was used 0.75 . The volume fractions range is between $1-4 \%$. Triangular channel score higher Nusselt number and lower friction factor than other cases against Reynolds number. When the volume fraction was increase, the Nusselt number increased and friction factor decreased, this gives $4 \%$ has the optimal properties.
\end{abstract}

Keywords: Forced convection, Ribbed-grooved channel, Heat transfer, 2-D flow.

\section{Introduction}

Heat transfer enhancement is the main object of this paper. Internal forced convection was applied in many heat transfer systems and processes, which include heating and cooling of fluids flowing inside conduits. Heat exchangers is a device used to transfer heat between a solid object and a fluid, or between two or more fluids.

In pipes, when carry cold and hot fluids, such as oils, steam, refrigerants, and other chemicals. In automotive systems, it includes fuel lines, exhaust system, and cooling system. Internal forced convection is also in application of air ducts which is used for heating and air conditioning. In heat exchanger, convection heat transfer is enhanced in thermal systems by many engineering application by reducing size, weight, and cost.

In various chemical process plants like heat exchanger, most heat transfer frequently utilized mode is forced convection. Ribs, wires, or grooves are welded on the surface to get roughness elements to improve heat transfer [1,2].

Numerical and experimental investigation of forced convective 2-D flow over grooved duct by Eiamsa and Promvonge [3]. 9 transverse grooves was set on the lower of incompressible air flow channel. They revealed that heat transfer can be enhanced by reverse re-circulation flow.

Groove geometry influence on turbulent heat transfer was studied by Abdulmajeed A. Ramadhan et.al [4]. "Four different geometries of grooved tube channel were selected (triangular, circular trapezoidal, and rectangular)". The tube length was set on $180 \mathrm{~cm}$, tube diameter was $5 \mathrm{~cm}$, and two groove depth to tube diameter ratios (e/D) were chosen 0.1 and 0.2. The range of Reynolds number was chosen from 10000 to 20000. CFD code was used to investigate this study. It is that heat transfer was improved by $64.4 \%$, maximum gain of 1.52 on thermal performance, and triangular grooves give highest thermal factor by as (e/D) of 0.1 .

Fathinia et.al 2012 [5] studied effect of types of fluid on 2-D grooves channel with turbulent of Reynolds number numerically. FVM, RNG $\mathrm{k}-\varepsilon$ simulation of model. Types of nanofluids are selected $\mathrm{Al}_{2} \mathrm{O}_{3}, \mathrm{ZnO}$, 
and $\mathrm{SiO}_{2}$ with respect to water was a base fluid. Volume fraction range was from 1 to $4 \%$ and diameter of nanoparticles was used from $20 \mathrm{~nm}$ to $50 \mathrm{~nm}$. The result show that $\mathrm{SiO}_{2}$ was best than other nanoparticles, and $20 \mathrm{~nm}$ is the best diameter and $4 \%$ volume fraction which improve heat transfer $114 \%$.

\section{Model Description}

\subsection{Physical Model}

A "Computational fluid dynamic" CFD analysis of 2-D lower triangular ribs channel between parallel plates that illustrated in Figure 1 that show 8 ribs and 9 grooves across bottom of duct. The entire length of channel (L) is $1870 \mathrm{~mm}$, and the height $(\mathrm{H})$ is set to be $\mathrm{H}=40 \mathrm{~mm}$. The width of groove (B) is set to be (3/4 $\mathrm{H}=30 \mathrm{~mm}$ ). Figures 2, 3, and 4 show Trapezoidal, Circular, and Rectangular channels w.r.t diameter of circular ribs $(\mathrm{D}=2 \mathrm{~S}=40 \mathrm{~mm})$. The entrance length $(20 \mathrm{H}=800 \mathrm{~mm})$ is regarded to create fully develop flow. The length of last rib is fixed by $(10 \mathrm{H}=400 \mathrm{~mm})$. The test section length (l) and rib height (S) is $670 \mathrm{~mm}$ and $20 \mathrm{~mm}$ respectively.

Rib length (s) is set to be $(5 / 4 \mathrm{H}=50 \mathrm{~mm})$. The ratio of groove width to channel height is set to be $(\mathrm{B} / \mathrm{H}=3 / 4)$.

\subsection{Boundary Conditions}

All boundary conditions for steady, incompressible, 2-dimensional flow. Uniform heat flux $\left(q^{\prime \prime}=500 \mathrm{~W} / \mathrm{m}^{2}\right)$ is applied on lower wall test section length. Mean inlet velocity is $10 \mathrm{~m} / \mathrm{s}$. It is assumed that the entering flow is at temperature $T_{\text {in }}=300 \mathrm{~K}$, and $T_{o}=293 \mathrm{~K}$ is the ambient temperature and zero pressure gradient at the exit, and at wall is no slip condition.

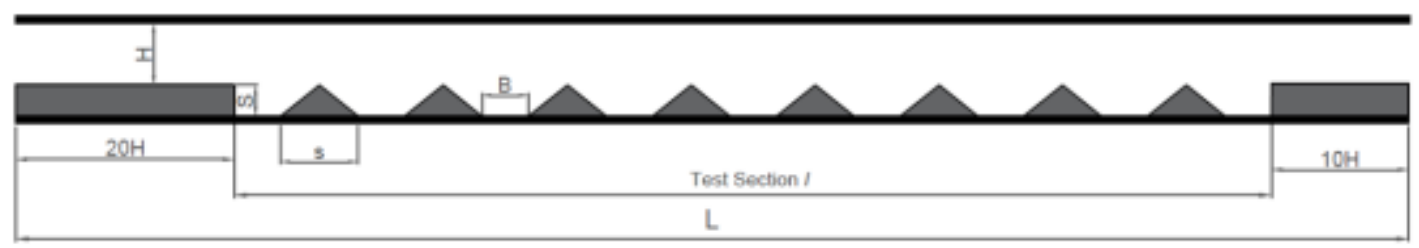

Figure 1 Triangular Ribs Channel

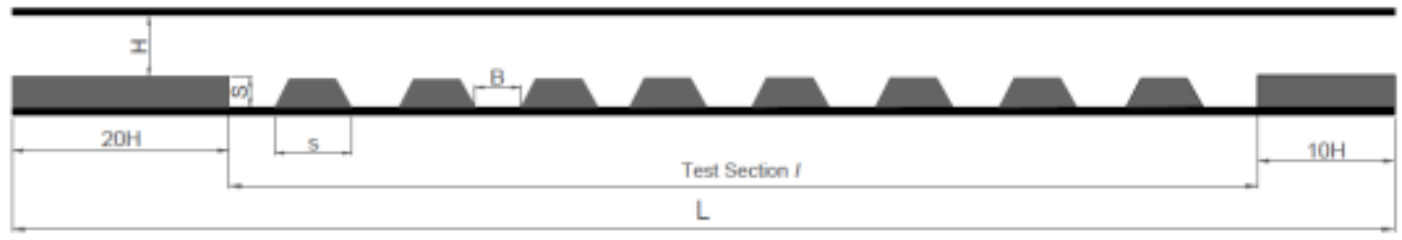

Figure 2 Trapezoidal Ribs Channel

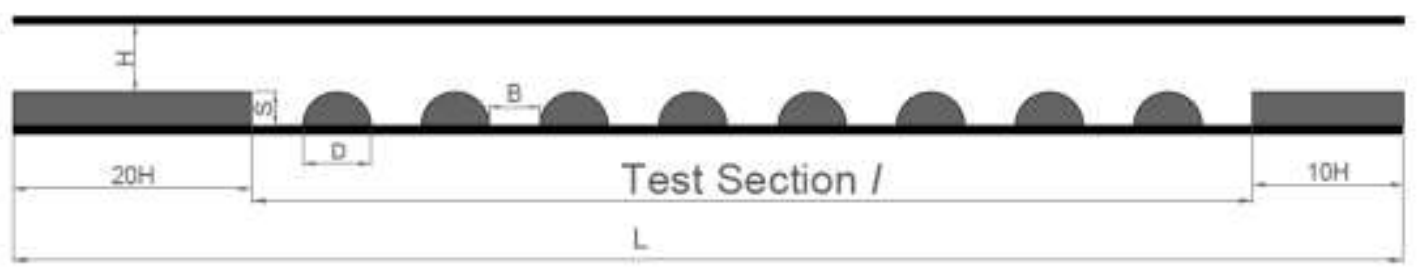

Figure 3 Circular Ribs Channel

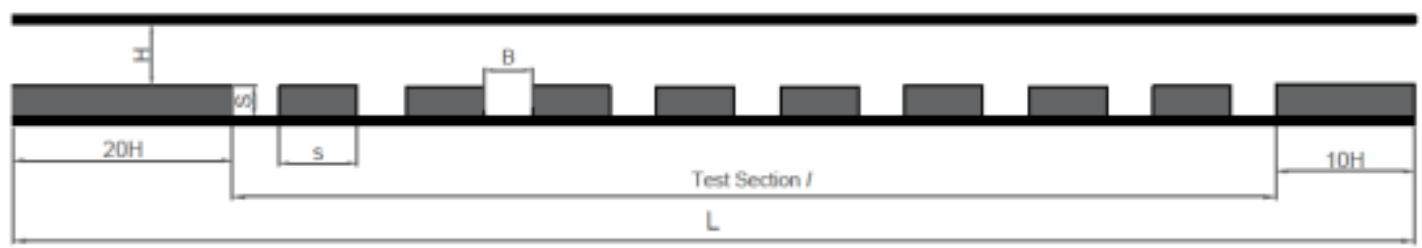

Figure 4 Rectangular Ribs Channel

\section{Mathematical modeling}

3.1 Governing equations 
Governing equations under previous conditions of "Continuity equation, Navier-Stokes equations and Energy equation" are as [6]:

Continuity equation:

$" \frac{\partial}{\partial x_{i}}\left(\rho u_{i}\right)=0 "$

Momentum equation:

$\frac{\partial}{\partial x_{i}}\left(\rho u_{i} u_{j}\right)=-\frac{\partial P}{\partial x_{i}}+\frac{\partial}{\partial x_{j}}\left[\mu\left(\frac{\partial u_{i}}{\partial x_{j}}+\frac{\partial u_{j}}{\partial x_{i}}\right)\right]+\frac{\partial}{\partial x_{i}}\left(-\rho \overline{u_{\imath}^{\prime} u_{j}^{\prime}}\right)$

Energy equation:

$" \frac{\partial}{\partial x_{i}}\left(\rho u_{i} T\right)=\frac{\partial}{\partial x_{j}}\left(\left(\Gamma+\Gamma_{t}\right) \frac{\partial T}{\partial x_{j}}\right) "$

Where $\Gamma$ is "molecular thermal diffusivity" and $\Gamma_{t}$ are "turbulent thermal diffusivity" have been given as:

$\Gamma=\frac{\mu}{P r}$, and $\Gamma_{\mathrm{t}}=\frac{\mu_{t}}{\operatorname{Pr}_{t}}$

In eq. (2), Reynolds stress $\left(-\rho \overline{u_{\imath}^{\prime} u_{\jmath}^{\prime}}\right)$ can be modeled by $\mathrm{k}-\varepsilon$ turbulence model. "The Boussinesq hypothesis is employed to relate the Reynolds stress to the mean velocity gradient":

$"-\rho \overline{u_{\imath}^{\prime} u_{\jmath}^{\prime}}=\mu_{t}\left(\frac{\partial u_{i}}{\partial x_{j}}+\frac{\partial u_{j}}{\partial x_{i}}\right) "$

The turbulence viscosity $\left(\mu_{t}\right)$ expression is computed from an appropriate turbulence model is given as:

$" \mu_{t}=\rho C_{\mu} \frac{k^{2}}{\varepsilon} "$

The modeled TKE is written as:

$\frac{\partial}{\partial x_{i}}\left(\rho k u_{i}\right)=\frac{\partial}{\partial x_{j}}\left[\left(\mu+\frac{\partial \mu_{t}}{\sigma_{k}}\right) \frac{\partial k}{\partial x_{j}}\right]+G_{k}-\rho \varepsilon$

TKE dissipation rate, $\varepsilon$, is similarly given by:

$\frac{\partial}{\partial x_{i}}\left(\rho \varepsilon u_{i}\right)=\frac{\partial}{\partial x_{j}}\left[\left(\mu+\frac{\partial \mu_{t}}{\sigma_{\varepsilon}}\right) \frac{\partial \varepsilon}{\partial x_{j}}\right]+C_{1 \varepsilon} \frac{\varepsilon}{k} G_{k}-C_{2 \varepsilon} \rho \frac{\varepsilon^{2}}{k}$

Where $(\rho \varepsilon)$ is TKE destruction rate, while $G_{k}$ its generation rate given by:

$" G_{k}=-\rho \overline{u_{\imath}^{\prime} u_{\jmath}^{\prime}} \frac{\partial u_{j}}{\partial x_{i}}$

The $\mathrm{k}-\varepsilon$ model constants can be chosen to be empirical constants [7] the turbulence transport equations is in Table 1

Table 1. Constants in $\mathrm{k}-\varepsilon$ turbulence model transport equations

\begin{tabular}{|c|c|c|c|c|c|}
\hline$C_{\mu}$ & $C_{1 \varepsilon}$ & $C_{2 \varepsilon}$ & $\sigma_{k}$ & $\sigma_{\varepsilon}$ & $P r_{t}$ \\
\hline 0.09 & 1.44 & 1.92 & 1.0 & 1.3 & 0.9 \\
\hline
\end{tabular}

The governing equations can be solved by utilizing CFD code FLUENT 6.3 with the standard k- $\varepsilon$ turbulence model and the SIMPLE algorithm. The convergence criteria of $10^{-6}$ and $10^{-4}$ are assumed for the residuals of energy and all other variables, respectively.

\subsection{Solution procedure}

Discretization of governing equations and turbulence model by using FVM and CFD was used to solve governing equations. For convective and diffusive terms, QUICK method was applied.

The setup is completed and number of iteration 250 is enough in Setup term.

Discretization of non-linear equations were implemented implicitly. SIMPLE method was chosen to estimate pressure field by velocity-pressure coupling algorithm.

Uniform velocity profile are applied at entrance region. The constant heat flux is set on bottom (test section) at same boundary conditions. Intensity of turbulence was kept $10 \%$ at entrance region. For the present case, friction factor $(f)$ and Nusselt number $(N u)$ are benefit parameters.

The friction factor can be estimated by pressure drop $(\Delta P)$ along test section length $(l)$.

$" f=\frac{\Delta P}{\frac{1}{2} \rho u_{a v}^{2}} \frac{D_{h}}{L} "$ 
Where $D_{h}=\frac{4 A_{c}}{P}$ is the hydraulic diameter.

The average Nusselt number may be obtained by:

$" N u=\frac{h D_{h}}{k_{f}}$

\subsection{Thermo physical properties of nanofluids}

The following equations were used to estimate the thermo physical properties of nanofluids. Table 2 below gives the thermo-physical properties of water and nanoparticle $\mathrm{SiO}_{2}$.

Table 2. Thermo-physical properties of materials

\begin{tabular}{|c|c|c|c|c|}
\hline & $\rho\left(\mathrm{kg} / \mathrm{m}^{3}\right)$ & $C p(\mathrm{~J} / \mathrm{kg} . \mathrm{K})$ & $K(\mathrm{~W} / \mathrm{m} . \mathrm{K})$ & $\mu(\mathrm{kg} / \mathrm{m} . \mathrm{s})$ \\
\hline $\mathrm{Water}$ & 998.2 & 4182 & 0.6 & $1.003 * 10^{-3}$ \\
\hline $\mathrm{SiO}_{2}$ & 2220 & 745 & 1.5 & -- \\
\hline
\end{tabular}

Effective Density [8]

$\rho_{n f}=(1-\phi) \rho_{f}+\phi \rho_{n p}$

The effective heat capacity is given as [8]:

$\left(\rho C_{p}\right)_{n f}=(1-\phi)\left(\rho C_{p}\right)_{f}+\phi\left(\rho C_{p}\right)_{n p}$

Where $\left(\rho C_{p}\right)_{f}$ and $\left(\rho C_{p}\right)_{n p}$ are heat capacities of base fluid and Nanoparticles, respectively.

The effective thermal conductivity equation of nanofluid is written as [8]:

$k_{\text {eff }}=k_{\text {static }}+k_{\text {Brwnian }}$

$k_{\text {static }}=k_{f}\left[\frac{\left(k_{n p}+2 k_{f}\right)-2 \phi\left(k_{f}-k_{n p}\right)}{\left(k_{n p}+2 k_{f}\right)+2 \phi\left(k_{f}-k_{n p}\right)}\right]$

$k_{\text {Brwnian }}=5 \times 10^{4} \beta \phi \rho_{f} C_{p, f}\left(\frac{K T}{2 \rho_{n p} R_{n p}}\right)^{0.5} f(T, \phi)$

Where $k_{n f}$ and $k_{f}$ are the thermal conductivities of nanoparticles and base fluid respectively.

Boltzmann Constant:

$k=1.3807 \times 10^{-23} \mathrm{~J} / \mathrm{K}$

$f(T, \phi)=\left(2.8217 \times 10^{-2} \phi+3.917 \times 10^{-2}\right)\left(\frac{T}{T_{o}}\right)+\left(-3.0669 \times 10^{-2} \phi-3.391123 \times 10^{-2}\right)$

For $1 \% \leq \phi \leq 4 \%$ and $300 \mathrm{~K}$, where $\mathrm{T}$ is the fluid temperature, and $\mathrm{T}_{0}$ is the reference temperature. The effective viscosity can be obtained using following mean empirical correlations [14]:

$\mu_{e f f}=\mu_{f} \times \frac{1}{\left(1-34.87\left(\frac{d_{p}}{d_{f}}\right)^{-0.3} \times \emptyset^{1.03}\right)}$

$d_{f}=0.1 *\left[\frac{6 M}{N \pi \rho_{f_{o}}}\right]^{\frac{1}{3}}$

Where $\mathrm{M}$ is the molecular weight of base fluid, $\mathrm{N}$ is the Avogadro number, and $\rho_{f_{o}}$ is the mass density of the based fluid calculated at temperature $\mathrm{T}_{0}=293 \mathrm{~K}$.

The effective thermal expansion is expressed as [8]:

$(\rho \beta)_{n f}=(1-\phi)(\rho \beta)_{f}+\phi(\rho \beta)_{n p}$

For different particle materials the $\beta$ equations are listed in Table 3 .

Table 3. $\beta$ Values for different particles

\begin{tabular}{|c|c|c|}
\hline Types of particles & $\beta$ & Concentration \\
\hline $\mathrm{SiO}_{2}$ & $1.9526(100 \phi)^{-1.4594}$ & $1 \% \leq \phi \leq 10 \%$ \\
\hline
\end{tabular}

\section{Numerical results}

\subsection{Grid independent}


For Triangular ribs channel, number of Nodes and Elements are taken of 22902 and 16719 respectively. For Trapezoidal ribs channel, number of nodes and elements were 21123 and 14461 respectively, and for semicircular 18770 nodes and 15107 elements, and for Rectangular ribs 25712 nodes and 18199 elements.

Additional increase in Nodes and Elements is lower than $1.5 \%$ variation of average Nusselt number that is taken a criterion for grid independence to save computer memory and calculation time. Figures $5 \mathrm{a}, \mathrm{b}, \mathrm{c}$, and $\mathrm{d}$ show mesh of fluid domain of (test section) in micro-channels for different shapes.

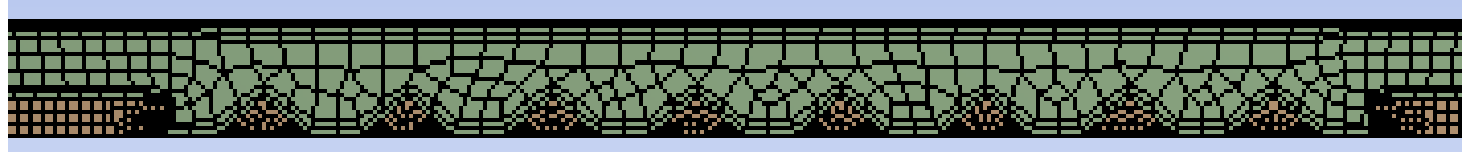

Figure 5 a. Mesh of Fluid Domain above the test section of Triangular ribs channel

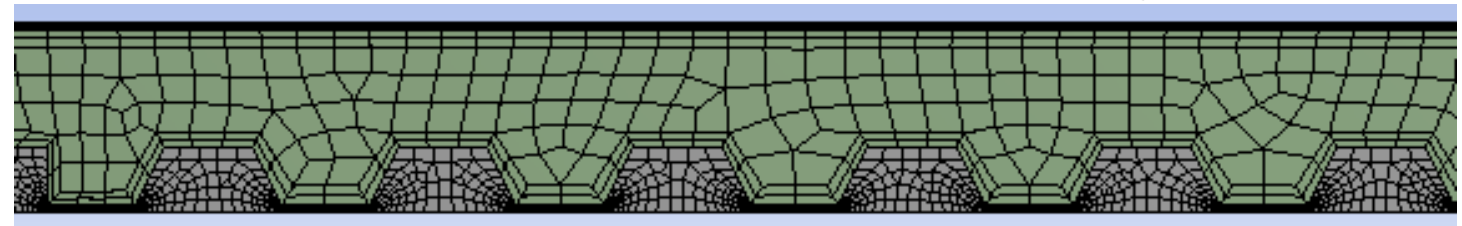

Figure 5 b. Mesh of Fluid Domain above the test section of Trapezoidal ribs channel

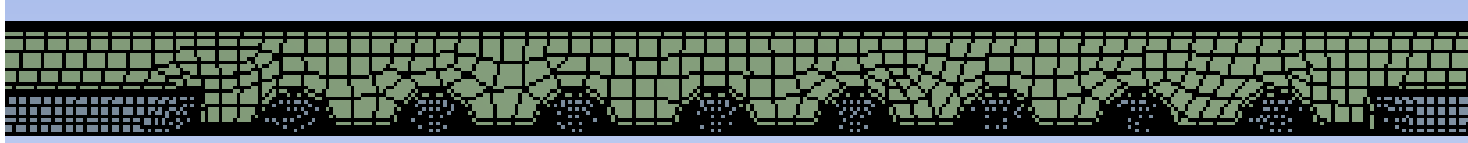

Figure 5 c. Mesh of Fluid Domain above the test section of Semi-circular ribs channel

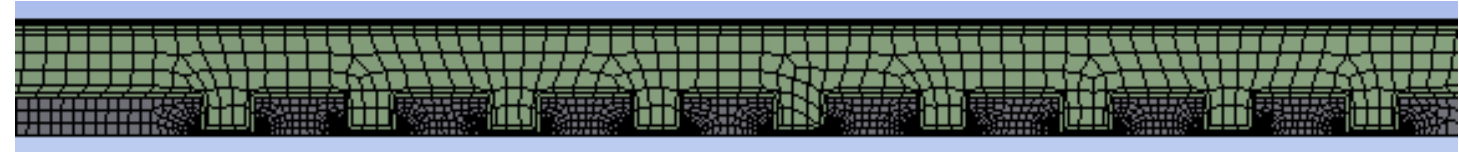

Figure $5 \mathrm{~d}$. Mesh of Fluid Domain above the test section of Rectangular ribs channel

\subsection{Validating the results}

In order to validate the results obtained from CFD code developed in present numerical study of Triangular, Trapezoidal, and Semi-circular ribs channel, the friction factor for turbulent convective heat of nanofluids in three geometric channel are calculated and compared with the previous experimental results of smooth channel and also with Rectangular ribs channel Fathinia et, al [5] as shown in Fig. 6 According to this figure, the results are in good agreement. Moreover, the average Nusselt number for this three geometrical channels compared with smooth channel and Rectangular ribs channel Fathinia et,al [5] as shown in Figure 7. From Fig. 7, it is found that the present results achieved better and higher Nusselt number than previous study.

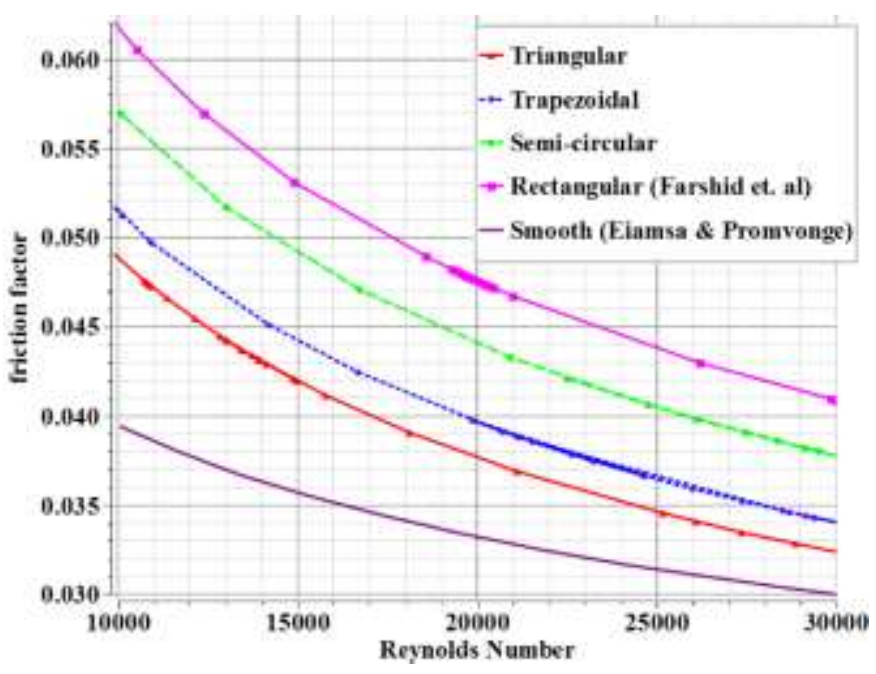

Figure 6 Comparison of the results variation of friction factor with Reynolds number 


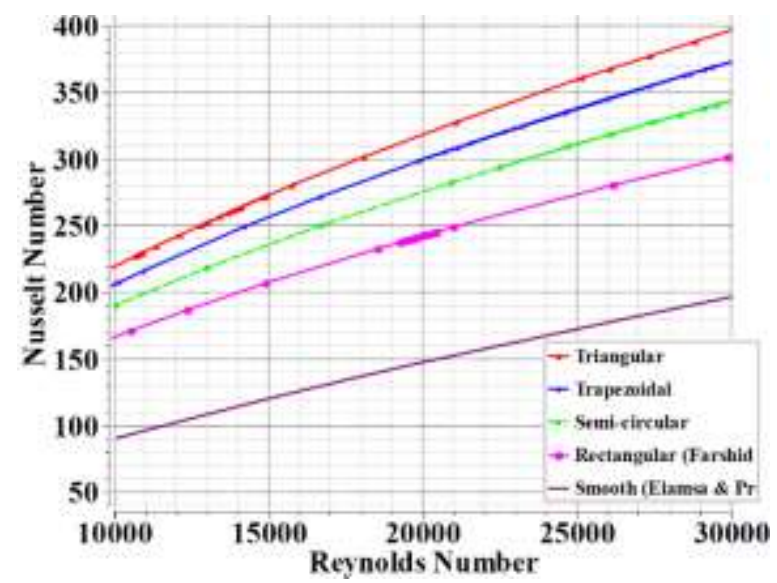

Figure 7 Comparison of the results variation of Nusselt number with Reynolds number

\section{Results and discussion}

The simulations present five types of channel (Triangular, Trapezoidal, Semi-circular, Rectangular ribs, and Smooth duct). Figure 6 above gives the results that friction factor decrease with increasing of Reynolds number values in different shape of channel, the results above give Smooth channel has lower and the Triangular ribs score lower than other ribs channel shapes. Figure 7 gives the Nusselt number increase with increasing Reynolds number, the results indicate that Triangular ribs channel have a higher Nusselt number than other case.

Triangular ribs channel used range of nanoparticles $\mathrm{SiO}_{2}$ volume fraction of $1 \% \leq \emptyset \leq 4 \%$ w.r.t nanoparticles diameter $d_{p}=20 \mathrm{~nm}$ and water is considered as a base fluid of nanoparticles. The results of friction factor and Nusselt number vs Reynolds number compare of multi-concentrations of nanofluid with water only. Figure 8 below gives friction factor decrease with increasing of volume fraction against Reynolds number.

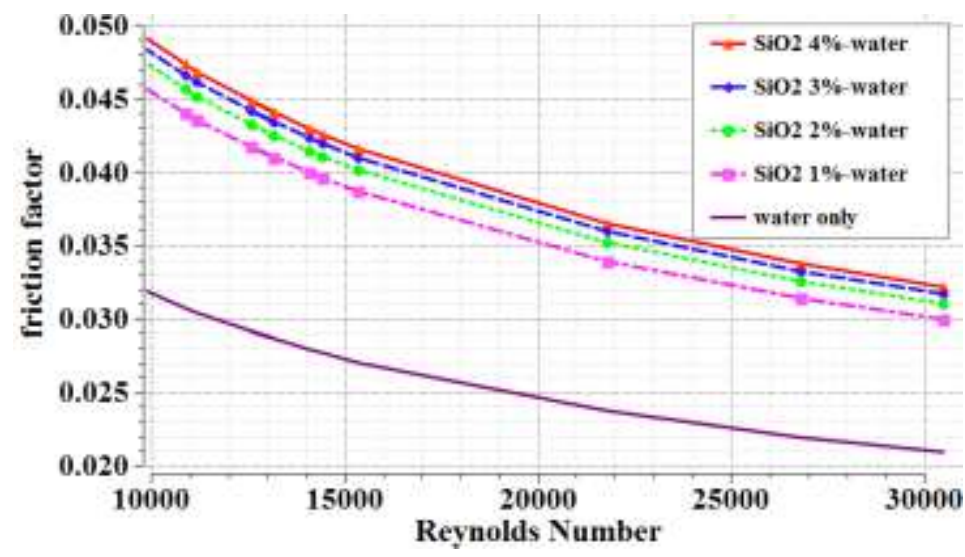

Figure 8 Effect of volume fraction on friction factor of $\mathrm{SiO}_{2}$ at different Reynolds number 


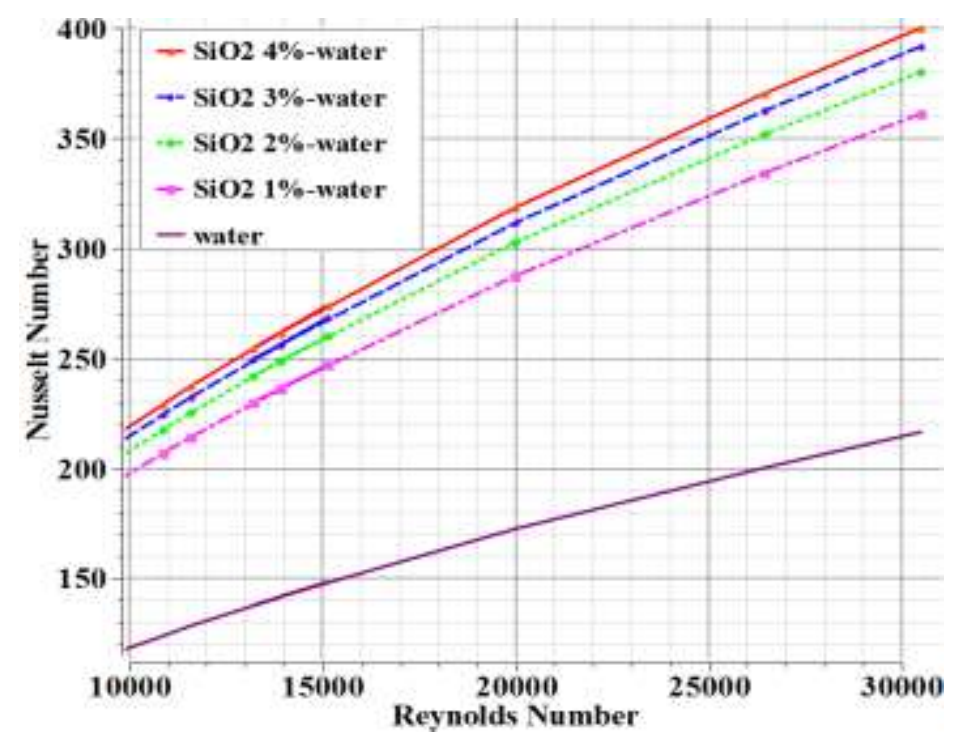

Figure 9 Effect of volume fraction on Nusselt number of $\mathrm{SiO}_{2}$ at different Reynolds number

The velocity contour and vector shown in Figure $10 \mathrm{a}$, and b notice that the velocity is decreasing when it was close to ribs in the test section because of the entropy and it is reach to $13 \mathrm{~m} / \mathrm{s}$ when it was close to upper channel wall. Pressure income is fully developed because of the first rectangular rib (20H).

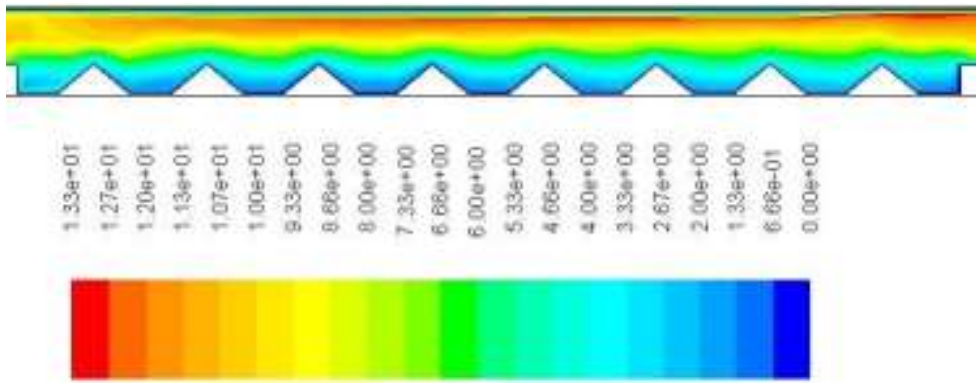

Figure 10 a. Velocity contour of Triangular Ribs Channel
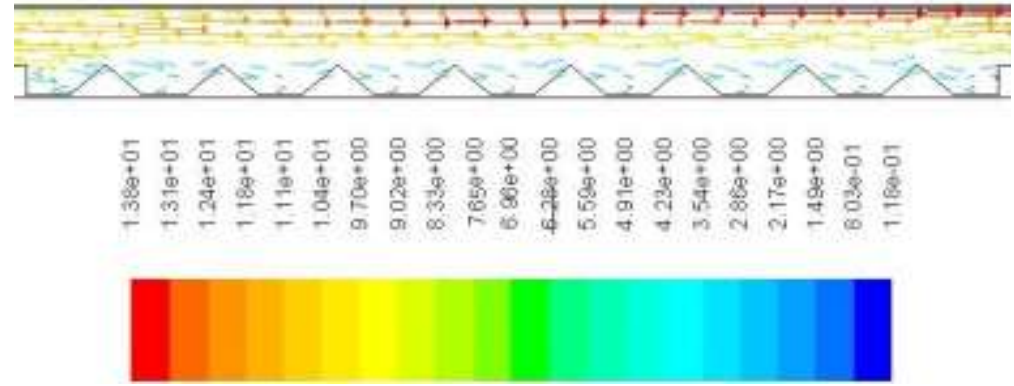

Figure 10 b. Velocity vectors of Triangular Ribs Channel

\section{Conclusion}

The investigation is analyzed of nanoparticles $\mathrm{SiO}_{2}$ and water as a base fluid by using "Finite Volume Method (FVM)" with $20 \mathrm{~nm}$ as diameter of nanoparticles. The heat flux is set on lower (Test section) of the channel and the upper wall is insulated. Five geometrical rib groove channel are studied (Triangular, 
Trapezoidal, Semi-circular, Rectangular, and Smooth duct) The Reynolds number range is from 10000 to 30000. The groove width to channel-height to ratio $(\mathrm{B} / \mathrm{H})$ of 0.75 . The results show that triangular ribs channel is the optimum selection to enhance heat transfer and fluid flow characteristics, rather than other cases. The increase of volume fraction of nanoparticles gives increase in Nusselt number and decrease in friction factor ( $4 \%$ is optimum choice of volume fraction).

\begin{tabular}{|c|c|c|c|}
\hline Symbol & Quantity & & \\
\hline$\overline{\mathbf{A}_{\mathbf{c}}}$ & Surface Area, $\mathrm{m}^{2}$ & $T$ & Temperature, $\mathrm{K}$ \\
\hline $\mathbf{B}$ & Distance between grooves, $\mathrm{mm}$ & $\boldsymbol{u}_{\boldsymbol{a} v}$ & Mean velocity, $\mathrm{m} / \mathrm{s}$ \\
\hline$\overline{C_{\mu}}$ & Turbulence model constant & $u_{i j}^{\prime}$ & Fluctuation velocity components \\
\hline $\mathbf{D}_{\mathrm{h}}$ & Hydraulic diameter of channel, $\mathrm{mm}$ & & \\
\hline$f$ & Friction factor & $C F D$ & Computational Fluid Dynamics \\
\hline $\mathbf{G}_{k}$ & TKE generation rate & QUICK & Quadratic Upstream Interpolation for \\
\hline $\boldsymbol{h}$ & Convective heat transfer coefficient & & Convective Kinetics scheme \\
\hline $\boldsymbol{H}$ & Channel height, mm & $R N G$ & Random Number Generation \\
\hline $\boldsymbol{k}$ & Turbulent kinetic energy & SIMPLE & Semi Implicit Method for Pressure \\
\hline$k_{f}$ & Thermal conductivity & & Linked Equations \\
\hline$l$ & Length of test section, $\mathrm{mm}$ & $T K E$ & Turbulent Kinetic Energy \\
\hline$L$ & Length of channel, mm & \multicolumn{2}{|c|}{ Greek symbols } \\
\hline $\mathrm{Nu}$ & Nusselt number & $\Gamma$ & Thermal diffusivity \\
\hline$p$ & Parameter, mm & $\varepsilon$ & Turbulent dissipation rate \\
\hline $\mathbf{P}$ & Static pressure, $\mathrm{Pa}$ & $\boldsymbol{\mu}$ & Kinematic viscosity \\
\hline $\operatorname{Pr}$ & Prandtl number & $\mu_{\mathrm{t}}$ & Eddy viscosity \\
\hline$q^{\prime \prime}$ & Heat flux, W/ m ${ }^{2}$ & $\rho$ & Density, $\mathrm{kg} / \mathrm{m}^{3}$ \\
\hline $\operatorname{Re}$ & Reynolds number & $\tau_{\mathrm{ij}}$ & Reynolds stress \\
\hline$s$ & Rib land/length, mm & $\tau$ & Wall shear stress \\
\hline$S$ & Rib height, mm & $\omega$ & Turbulent specific dissipation rate \\
\hline
\end{tabular}

\section{References}

[1] Karwa R, Solanki SC, Saini JS (1999) Heat transfer coefficient and friction factor correlations for the transitional flow regime in rib-roughened rectangular ducts. Int J Heat Mass Transf 42(9):1597-1615

[2] San JY, Huang WC (2006) Heat transfer enhancement of transverse ribs in circular tubes with consideration of entrance effect.Int J Heat Mass Transf 49(17-18):2965-2971

[3] S.Eiamsa-ard, P.Promvonge, Numerical study on heat transfer of turbulent channel flow over periodic grooves. International Communications in Heat and Mass Transfer, 35, pp. 844-852, 2008.

[4] Abdulmajeed A. Ramadhan et,al, Groove geometry effects on turbulent heat transfer and fluid flow. Int J Heat Mass Transf 49:185-195, 2008. 
[5] Fathinia et.al, Turbulent Forced Convection Flow in a Channel over Periodic Grooves using Nanofluids. World Academy of Science, Engineering and Technology, Vol: 6, No: 12, 2012.

[6] A.A. Al-aswadi, H.A.M., N.H. Shuaib, Antonio Campo, Laminar forced convection flow over a backward facing step using nanofluids. International Communications in Heat and Mass Transfer, vol 37, 2010.

[7] Launder BE, Spalding DB (1972) Lectures in mathematical models of turbulence Academic Press, London.

[8] S. A.Sh. Kherbeet, H.A.M., B.H. Salman, The effect of nanofluids flow on mixed convection heat transfer over microscale backward-facing step. International Journal of Heat and Mass Transfer, 2012. 